\title{
Fabrication of Reflective Color Films from Cellulose Derivatives
}

\author{
Hibiki Shimokawa ${ }^{1}$, Kenichiro Hayata ${ }^{2}$, Masashi Fukawa ${ }^{2}$, and Seiichi Furumi ${ }^{2,3^{*}}$ \\ ${ }^{1}$ Department of Chemistry, Faculty of Science Division 1, \\ ${ }^{2}$ Department of Chemistry, Graduate School of Science, \\ ${ }^{3}$ Department of Applied Chemistry, Faculty of Science Division 1, \\ Tokyo University of Science, 1-3 Kagurazaka, Shinjuku, Tokyo 162-8601, Japan \\ *furumi@rs.tus.ac.jp
}

\begin{abstract}
In this study, we fabricated the reflective color films of lyotropic cholesteric liquid crystals (CLCs) by using a hydroxypropyl cellulose (HPC) derivative and water. When HPC derivatives possessing acryloyl esters in the side chains (HPC-AcE) were completely dissolved in water to form the lyotropic CLC ( $\mathrm{HPC}-\mathrm{AcE} \mathrm{H}_{2} \mathrm{O}$ ), we could observe Bragg reflection in the visible wavelength range at room temperature. Furthermore, after the lyotropic CLC mixtures were irradiated with UV light, the reflection colors could be preserved at room temperature. This report has established an important guideline to fabricate the colored CLC cellulose films with safety and low risks for both human being and global environment from naturally occurring polymers and water.
\end{abstract}

Keywords: Cellulose, Cholesteric liquid crystals, Lyotropic liquid crystals, Bragg reflection, Color

\section{Introduction}

Cellulose is the most abundant natural polymer on the planet earth, and therefore is one of low-cost biomasses with safety and low risks for global environment. Currently, cellulose derivatives have been widely used in coatings, laminates, and optical films [1,2]. Hydroxypropyl cellulose (HPC, Fig. 1), one of the cellulose derivatives, is commercially available for food and pharmaceutical additives. From the viewpoint of liquid crystalline materials, HPC is well-known to form the lyotropic cholesteric liquid crystal (CLC) phase in water at the relatively high concentration of HPC [3-9]. In the CLC phase, the chiral molecules are selfassembled into the periodic helicoidal molecular structures, thereby leading to the emergence of unique optical property of selective light reflection. Such a reflection phenomenon corresponds to a kind of Bragg reflection. The maximum wavelength of selective reflection $(\lambda)$ is numerically expressed as the following formula:

$$
\lambda=n p
$$

where $p$ means the helical pitch length, and $n$ is the average refractive index of CLC materials [10]. The helical pitch length of $p$ can be tuned by temperature, electric field, magnetic field, and so on, thereby resulting the on-demand control of reflection colors by such external stimuli.

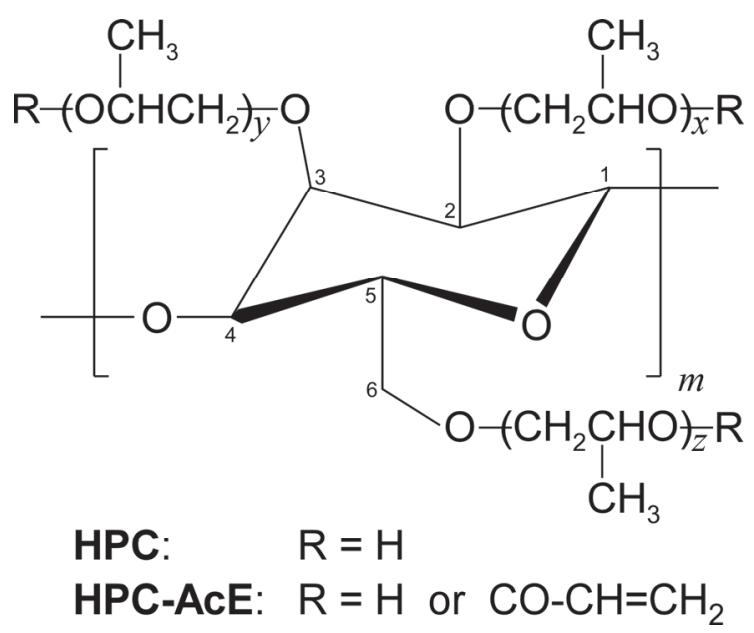

Fig. 1. Chemical structures of hydroxypropyl cellulose (HPC) and its derivative possessing acryloyl esters in the side chains (HPC-AcE). 
The HPC derivatives, whose side chains are chemically modified in an appropriate manner, form lyotropic CLC phase when they are dissolved in liquid monomers such as acrylates or methacrylates [11-17]. Subsequently, after such lyotropic CLCs are irradiated with UV light, the solid-state films with various reflection colors can be fabricated by the photopolymerization or photocrosslinking reaction, arising from the permanent preservation of helical molecular structures [13-17]. However, many of these liquid monomers are harmful to the human health due to their volatility by low boiling points. Unfortunately, such employment of liquid monomers would lose the advantages of HPC which has low risks on the human health. Very recently, we have reported on the preparation of lyotropic CLCs with visible reflection by dissolving an HPC derivative tethering propionyl side chains in a fragrance liquid, that is, $\alpha$-ionone [18]. Although this is a human-friendly lyotropic CLC mixture, we could not fabricate the solid-state films with reflection colors.

This situation motivates us to fabricate the reflective color films with low risks to human health as well as environment by using water instead of liquid monomers [19]. Since it is necessary to adopt liquid monomers for the lyotropic CLC mixtures or to use the thermotropic CLCs of crosslinkable cellulose derivatives for the formation of solid-state films by polymerization or crosslinking reaction, our attention has been focused on the crosslinkable HPC derivatives. However, the previously reported crosslinkable HPC derivatives do not dissolve in water, because most of the hydroxyl groups in the side chains are chemically modified with hydrophobic alkanoyl groups. In this article, in order to improve the affinity of HPC derivatives with water, we synthesized a series of hydrophilic, crosslinkable HPC derivatives with slight introduction of acryloyl ester groups in the side chains. In other words, almost remaining hydroxyl groups of HPC would lead to the enhancement of water solubility. By preparing the lyotropic CLC mixtures of HPC derivatives in water, we attempted to fabricate the reflective color films of cellulose derivatives with low risks for both human health and global environment.

\section{Experimental}

\subsection{Materials}

Figure 1 shows the chemical structures of HPC and its derivative possessing acryloyl ester groups in the side chains (HPC-AcE). In order to synthesize HPC-AcE, we used a commercially available reagent of HPC (Fujifilm Wako Pure Chemical Industries, Ltd.; Viscosity of $2.0 \mathrm{wt} \%$ aqueous solution, $2.0 \sim 2.9 \mathrm{mPa} \cdot \mathrm{s}$; Weight average molecular weight, $M_{w}=2.8 \times 10^{4}$; Number average molecular weight, $M_{n}=1.1 \times 10^{4}$ ) as the starting material. By measuring the ${ }^{1} \mathrm{H}-\mathrm{NMR}$ spectrum of pristine $\mathrm{HPC}$ in $\mathrm{CDCl}_{3}$, the average number of chemically combined propylene oxide per anhydroglucose unit (Molecular substitution; $M S$ ) was calculated to be $\sim 4.0$ according to a previous report [20]. As a result, the $M S$ value denotes the sum of $x, y$ and $z$, as given in Fig. 1.

A series of HPC-AcE derivatives with different modification degrees of acryloyl ester groups $(A c E)$ were synthesized according to the following simple procedure. After HPC (3.0 g) was dried under reduced pressure for 12 hours or more in advance, we prepared a solution of HPC in ultra-dehydrated acetone $(15 \mathrm{~mL})$. After that, acryloyl chloride (Tokyo Chemical Industry Co., Ltd.) of $0.02 \mathrm{~mL}$, $0.06 \mathrm{~mL}$, or $0.2 \mathrm{~mL}$ was dropwise added into the HPC solution to control three kinds of $A c E$ values. The reaction mixture was intently stirred at room temperature under dark condition for 5 days. After the solvent was removed by using an evaporator, the residue was dried under reduced pressure at room temperature for 2 days to completely exclude acetone. When HPC was reacted with acryloyl chloride of $0.02 \mathrm{~mL}$ and $0.06 \mathrm{~mL}$, these HPC derivatives showed white solid. In contrast, in the case of addition of acryloyl chloride at $0.2 \mathrm{~mL}$, HPC-AcE exhibited slightly yellow solid.

In order to prepare the lyotropic CLC mixtures of HPC-AcE, we adopted ultrapure water as the solvent for preparation of the lyotropic CLC mixtures and 2-hydroxy-4'-(2-hydroxyethoxy)-2methylpropiophenone (HHEMPP; Tokyo Chemical Industry Co., Ltd.) as the photoinitiator of free radicals. The lyotropic CLC mixtures (HPCAcE $\mathrm{H}_{2} \mathrm{O}$ ) were prepared by completely dissolving HPC-AcE in water at various concentrations between $64 \mathrm{wt} \%$ and $72 \mathrm{wt} \%$, followed by addition of HHEMPP at $0.05 \mathrm{wt} \%$ in the mixture to proceed the photocrosslinking reaction of HPC-AcE in water.

\subsection{Fabrication of CLC cells}

Following our recent reports [16,21], we fabricated the CLC cells of HPC-AcE_ $\mathrm{H}_{2} \mathrm{O}$ mixture. The CLC cell gap was adjusted by using polytetrafluoroethylene film spacers with the thickness of $\sim 500 \mu \mathrm{m}$. In order to obtain the 
photocrosslinked lyotropic CLC of HPC-AcE_ $\mathrm{H}_{2} \mathrm{O}$ mixture, we irradiated with UV light from a $150 \mathrm{~W}$ Hg-Xe lamp (San-ei Electric Mfg. Co., UV Supercure-203S) equipped with long-pass and band-pass filters (Toshiba, UV-35 and UVD-36A) to isolate an emission line at $365 \mathrm{~nm}$. The light intensity was measured by a photodiode sensor (Ophir, PD300-UV) equipped with a PC interface (Ophir, Smart Head to USB Interface). Photoirradiation was performed with UV light with $\sim 9.0 \mathrm{~mW} / \mathrm{cm}^{2}$ for 20 minutes at room temperature.

\section{Results and discussion}

\subsection{Syntheses of HPC-AcE}

As the pristine HPC was reacted with acryloyl chloride of $0.02 \mathrm{~mL}, 0.06 \mathrm{~mL}$, or $0.2 \mathrm{~mL}$, we obtained a series of HPC-AcE derivatives in the reaction yields of $\sim 90 \%$. After the HPC-AcE syntheses, we compared FT-IR spectral change before and after esterification of HPC with acryloyl chloride. We observed clearly appearance of a sharp band around $1700 \mathrm{~cm}^{-1}$ due to $\mathrm{C}=\mathrm{O}$ stretching vibration of HPC-AcE, and remaining of a broad band in a range from $3000 \mathrm{~cm}^{-1}$ to $3600 \mathrm{~cm}^{-1}$ attributed to $\mathrm{O}-\mathrm{H}$ stretching vibration of the terminal $\mathrm{OH}$ groups of HPC. This result implies that some of $\mathrm{OH}$ groups of HPC are esterified by acryloyl chloride and most of the $\mathrm{OH}$ groups remain intact. From the ${ }^{1} \mathrm{H}-\mathrm{NMR}$ spectra of three kinds of HPC-AcE derivatives, it was found that unreacted acryloyl chloride was completely removed by evaporation after the syntheses. However, it is anticipated that a small amount of hydrogen chloride as a by-product of this reaction would remain in the HPC-AcE derivatives (vide infra). In addition, we numerically evaluated the esterification degrees of acryloyl side chains $(A c E)$ from the ${ }^{1} \mathrm{H}-\mathrm{NMR}$ spectra. As a result, the $A c E$ values were calculated as $0.03,0.09$, and 0.31 according to the reacted amount of acryloyl chloride at $0.02 \mathrm{~mL}, 0.06 \mathrm{~mL}$, and $0.2 \mathrm{~mL}$, respectively. As shown in Fig. 1, since the maximum $A c E$ value corresponds to 3.0, we succeeded in the syntheses of a series of HPC-AcE derivatives with quite low $A c E$ values.

3.2. Reflection properties of lyotropic HPCAcE_ $\mathrm{H}_{2} \mathrm{O}$ mixtures

After two kinds of HPC-AcE derivatives with $A c E=0.03$ and 0.09 were completely dissolved in water, we observed lyotropic CLC phase with visible reflection features. These lyotropic mixtures of HPC-AcE inevitably showed slight acidity such as $\mathrm{pH}$ of $\sim 4.0$, which was relied on the mixing ratio of HPC-AcE and water, due to the remaining hydrogen chloride, as mentioned in the preceding section. Nevertheless, the refection peaks of lyotropic CLCs of HPC-AcE and water remained intact even after gentle storing for at least 1 month. Therefore, it is plausible that the remaining hydrogen chloride have no harmful influence on the helicoidal molecular structure of lyotropic CLCs. In contrast, we could not prepare lyotropic CLC of HPC-AcE with $A c E=0.31$ in water due to its low solubility in water. Because the residual hydroxyl groups of HPC-AcE are insufficient for dissolving in water at such high $A c E$ values over 0.31 . Figure 2 (a) shows the transmission and reflection spectra of lyotropic CLC mixtures of HPC-AcE $\mathrm{H}_{2} \mathrm{O}$ with different concentrations of HPC-AcE $(A c E=0.09)$. We observed Bragg reflection in the visible wavelength range at room temperature in the concentration range between $64 \mathrm{wt} \%$ and $72 \mathrm{wt} \%$. It turned out that the reflection peak shifts to the longer wavelength as the concentration of HPC-AcE was
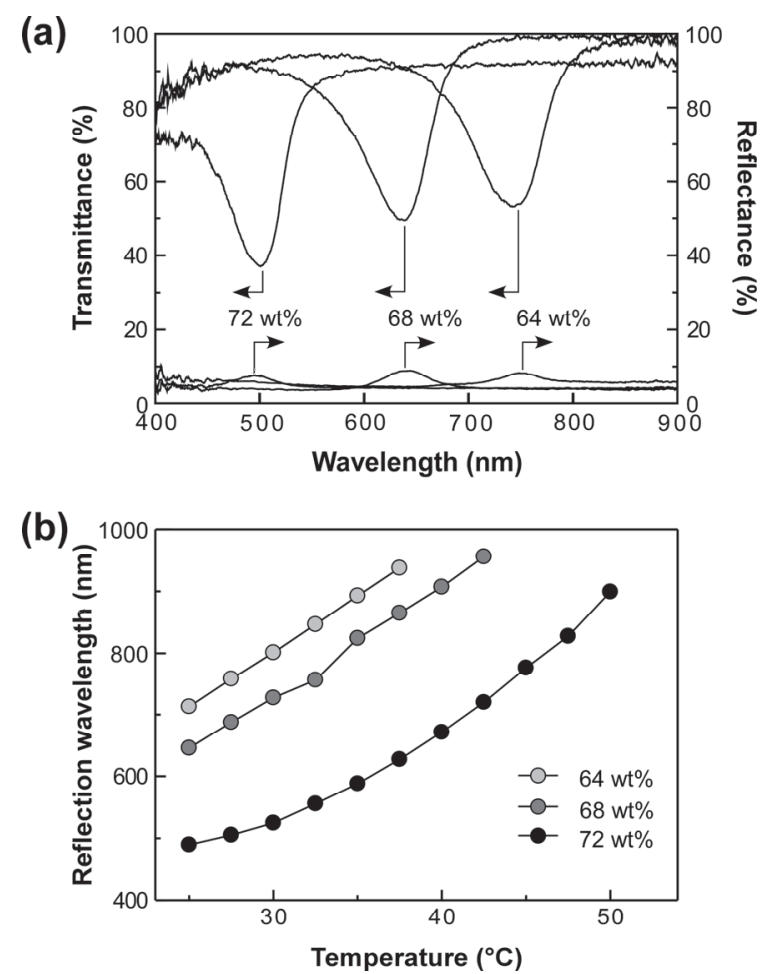

Fig. 2. (a) Changes in transmission and reflection spectra of CLC cells of lyotropic CLCs of HPCAcE_ $\mathrm{H}_{2} \mathrm{O}$ as a function of the concentration of HPC$\operatorname{AcE}(A c E=0.09)$. (b) Temperature dependences of the reflection peak wavelengths of lyotropic CLC cells prepared at various concentrations of HPC-AcE from 64 wt $\%$ to $72 \mathrm{wt}^{\circ} \%$. 
diluted with water. In other words, the reflection peak wavelength could be tuned by the content of water in lyotropic CLCs. This suggests that the helical pitch length is expanded by impregnating water in the molecular helical structure of CLC.

Figure 2 (b) compiled the temperature dependences of Bragg reflection peak wavelengths of lyotropic HPC-AcE $\mathrm{H}_{2} \mathrm{O}$ mixtures which were prepared at the concentrations of HPC-AcE $(A c E=$ $0.09)$ in $\mathrm{H}_{2} \mathrm{O}$ in the concentration range from 64 $w t \%$ to $72 \mathrm{wt} \%$. For example, when $72 \mathrm{wt} \%$ of HPC-AcE_ $\mathrm{H}_{2} \mathrm{O}$ was gradually heated from $25^{\circ} \mathrm{C}$ to $50{ }^{\circ} \mathrm{C}$, the reflection peak continuously shifted from $400 \mathrm{~nm}$ to $900 \mathrm{~nm}$. Similarly, the thermally induced shifting behavior of reflection peak was observed for the lyotropic CLC of HPC-AcE (AcE $=0.03$ ) in water. At first glance, it seems that the reflection wavelength shift range upon heating process is wider than those of the previously reported lyotropic and thermotropic CLCs $[17-19,22]$. This is probably because water has a relatively high value of thermal volume expansion

(a)

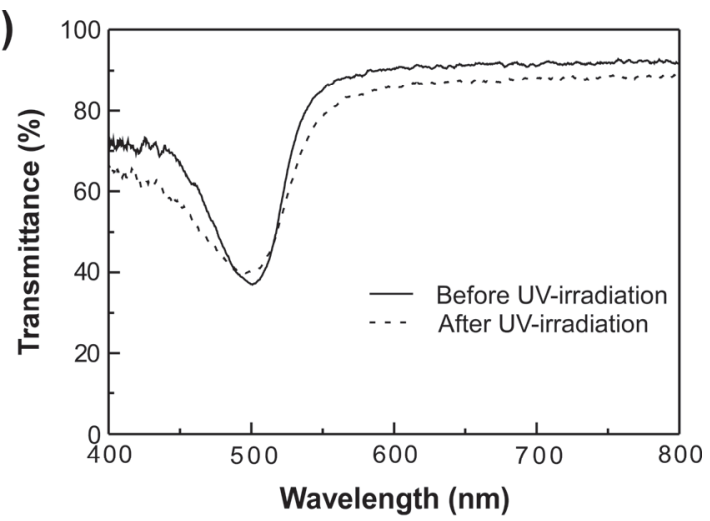

(b)

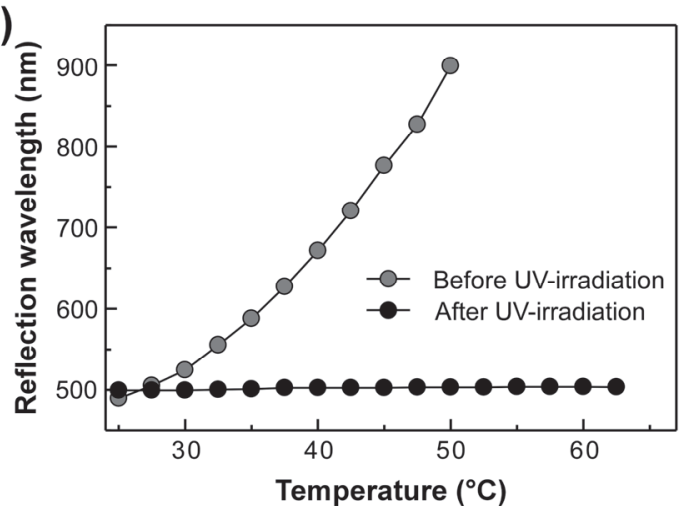

Fig. 3. (a) Transmission spectral change of a CLC cell of $\mathrm{HPC}-\mathrm{AcE} \mathrm{H}_{2} \mathrm{O}$ mixture, prepared from HPC-AcE $(A c E=0.09)$ at $72 \mathrm{wt} \%$ in water, before and after irradiation with UV light. (b) Temperature dependences of Bragg reflection wavelengths of the CLC cell of lyotropic HPC-AcE_ $\mathrm{H}_{2} \mathrm{O}$ mixture before and after UV-irradiation. coefficient, resulting in widely expanding the molecular helical pitch.

\subsection{UV-irradiation of HPC-AcE $\mathrm{H}_{2} \mathrm{O}$}

Figure 3 (a) shows the change in transmission spectra of the lyotropic CLC of $72 \mathrm{wt} \%$ HPC-AcE $(A c E=0.09)$ in water before and after photoirradiation with UV light. Although the reflection wavelength was slightly shifted after irradiation with UV light, we obtained a CLC film maintaining the reflection color. We presumed that a small amount of water in the molecular helical structure evaporates by heat generated at the time of UV-irradiation, resulting in the slight shrinkage of CLC helical pitch. When we carried out the similar experiment using HPC-AcE $(A c E=0.03)$, the reflected color could not be immobilized even after irradiation with UV light. This fact suggests that the molecular helical structure cannot be immobilized owing to its quite low $A c E$ value of 0.03 .

As shown in Fig. 3 (b), we compared the temperature dependences of Bragg reflection wavelengths of the CLC cell of lyotropic HPCAcE_ $\mathrm{H}_{2} \mathrm{O}$ mixture, prepared at $72 \mathrm{wt} \%$ of HPCAcE, before and after UV-irradiation. Before UVirradiation, the reflection peak shifted to the longer wavelength of infrared region such as $900 \mathrm{~nm}$ by elevating the temperature from $25^{\circ} \mathrm{C}$ to $50{ }^{\circ} \mathrm{C}$. However, the photocrosslinked CLC film showed constantly the reflection peak of $500 \mathrm{~nm}$ even by heating at $\sim 63^{\circ} \mathrm{C}$. This implies that the molecular helical structure of CLC is completely immobilized by photocrosslinking reaction, resulting in no change of the helical pitch upon heating process. As heated over $63{ }^{\circ} \mathrm{C}$, the CLC film became cloudy and the reflection peak disappeared. HPC is known to show a lower critical solution temperature (LCST) at $43{ }^{\circ} \mathrm{C}$ in water [23]. HPC-AcE has acryloyl ester groups in the side chains. Therefore, it is anticipated that the photocrosslinked CLC film has an LCST at a higher temperature of around 63 ${ }^{\circ} \mathrm{C}$. When the color film of HPC-AcE was heated over $63{ }^{\circ} \mathrm{C}$, the reflection peak thoroughly disappeared due to phase separation. Finally, we attempted patterning by adjusting the intensity of UV light according to our previous report [17]. As a result, we successfully demonstrated the preparation of photopatterned films from lyotropic CLC mixtures of HPC-AcE and water. In this way, the color films of lyotropic CLCs can be expected to be applied as versatile photonic devices with lower risk for both human health and global 
environment.

\section{Conclusion}

In this study, we prepared water-soluble, crosslinkable HPC derivatives in order to improve the affinity in water by introducing a small amount of acryloyl ester groups into the side chains of HPC. Due to most of remaining hydroxyl groups of HPC, we successfully obtained lyotropic CLC mixtures with visible reflection by using water as the solvent. By the appropriate concentration of HPC-AcE, the reflection peak was tuned in the visible wavelength range at room temperature. In addition, the reflection peaks of lyotropic CLC mixtures shifted to the longer wavelength by elevating the temperature. Furthermore, we succeeded in the fabrication of photocrosslinked CLC films with reflection colors by irradiation with UV light. Such color CLC films exhibited constantly the reflection peak even when heated up to $60{ }^{\circ} \mathrm{C}$. Thus, these CLC films could be fabricated from crosslinkable HPC derivatives and water. Therefore, the strategic concept addressed here would contribute to the fabrication of nextgeneration photonic devices that have low risks for both environment and human health for our sustainable future.

\section{Acknowledgements}

This research was supported in part by the Ministry of Education, Science, Sports and Culture of Japan under the Grant-in-Aid for Scientific Research (B) (No. 25288103), Shorai Foundation for Science and Technology, and NEXCO Group Companies' Support Fund to Disaster Prevention Measures on Expressways.

\section{References}

1. J. Kim, S. Yun, and Z. Ounaies, Macromolecules, 39 (2006) 4202.

2. W. Yuan, J. Zhang, H. Zou, T. Shen, and J. Ren, Polymer, 53 (2012) 956.

3. R. S. Werbowyj and D. G. Gray, Mol. Cryst.
Liq. Cryst., 34 (1976) 97.

4. H. Fischer, M. Murray, A. Keller, and J. A. Odell, J. Mater. Sci., 30 (1995) 4623.

5. R. S. Werbowyj and D. G. Gray, Macromolecules, 13 (1980) 69.

6. R. S. Werbowyj and D. G. Gray, Macromolecules, 17 (1984) 1512.

7. J. Bheda, J. F. Fellers, and J. L. White, Colloid Polym. Sci., 258 (1980) 1335.

8. Y. Onogi, J. L. White, and J. F. Fellers, J. NonNewton. Fluid Mech., 7 (1980) 121.

9. F. Fried, J. M. Gilli, and P. Sixou, Mol. Cryst. Liq. Cryst., 98 (1983) 209.

10. S. Furumi, Chem. Rec., 10 (2010) 396.

11. S.-L. Tseng, A. Vakente, and D. G. Gray, Macromolecules, 14 (1981) 715

12. S.-L. Tseng, G. V. Laivins, and D. G. Gray, Macromolecules, 15 (1982) 1262.

13. M. Müller, R. Zentel, and H. Keller, $A d v$. Mater, 9 (1997) 159.

14. M. Müller and R. Zentel, Macromol. Chem. Phys., 201 (2000) 2055.

15. R. Chiba, Y. Nishio, Y. Sato, M. Ohtaki, and Y. Miyashita, Biomacromolecules, 7 (2006) 3076.

16. M. Fukawa, K Suzuki, and S. Furumi, $J$. Photopolym. Sci. Technol., 31 (2018) 563.

17. R. Aoki, M. Fukawa, and S. Furumi, J. Photopolym. Sci. Technol., 32 (2019) 651.

18. A. Kawaguchi, R. Aoki, K. Hayata, M. Furukawa, M. Fukawa, and S. Furumi, J. Photopolym. Sci. Technol., 32 (2019) 639.

19. M. Fukawa, A. Kawaguchi, K. Hayata, R. Aoki, M Furukawa, and S. Furumi, J. Photopolym. Sci. Technol., 32 (2019) 633.

20. F. F.-L. Ho, R. R. Kohler, and G. A. Ward, Anal. Chem., 44 (1972), 178.

21. K. Hayata and S. Furumi, Polymers, 11 (2019) 1696.

22. K. Hayata, T. Suzuki, M. Fukawa, and S. Furumi, J. Photopolym. Sci. Technol., 32 (2019) 633.

23. Y. Uraki, T. Imura, T. Kishimoto, and $\mathrm{M}$. Ubukata, Carbohydr. Polym., 58 (2004) 123. 